\title{
Desastres naturales, destrucción creativa y gentrificación: estudio de casos comparados en Sevilla (España), Ciudad de México (México) y Talca (Chile) ${ }^{1}$
}

\author{
Jorge Inzulza-Contardo² e Ibán Díaz Parra ${ }^{3}$
}

\begin{abstract}
RESUMEN
El presente trabajo explora el rol de los desastres naturales en los procesos de desvalorización y revalorización, declive y gentrificación de la ciudad central. En este sentido, se argumenta la importancia que han adquirido estos desastres dentro de las operaciones de renovación urbana y dentro de una lógica de destrucción creativa. El estudio de casos comparados en Sevilla (España), Ciudad de México (México) y Talca (Chile), muestran que los desastres naturales han sido claves en la desvalorización de los espacios centrales, tanto como en su revalorización posterior. Se concluye que más que un efecto mecánico, la relación entre desastres naturales, renovación urbana y gentrificación resulta un campo estratégico que puede orientarse tanto a operaciones especulativas como de carácter social. Se sugiere entonces que las políticas urbanas y los desastres naturales deberían ser parte de la misma agenda política, que contemple los procesos de reconstrucción en su amplio espectro.
\end{abstract}

Palabras clave: Desastre natural, destrucción creativa, gentrificación, reconstrucción

\begin{abstract}
This paper explores the role of natural disasters in the processes of devaluation, and revaluation, decline and gentrification in the city center. In this sense, we argue that natural disasters are key protagonists in urban renewal strategies, and are part of a creative destruction approach. The comparative case studies in Seville (Spain), Mexico City (Mexico) and Talca (Chile) show that natural disasters have been crucial facts in the devaluation of centrally located areas, as well as their subsequent revaluation stage. The paper concludes that the relationship between natural disasters, urban renewal and gentrification is more than a mechanical effect, rather it is a strategic field that can be oriented toward either speculative interventions and social approaches. Thus, we suggested that urban policies and natural disasters should be part of a same politic agenda, which includes all the reconstruction stages.
\end{abstract}

Key words: Natural disaster, creative destruction, gentrification, reconstruction

\footnotetext{
1 El presente trabajo forma parte del Proyecto Fondecyt de Iniciación 11140181 "Diseño cívico resiliente en la ciudad intermedia frente a procesos de gentrificación y reconstrucción. Estudios de barrios históricos en Talca, Chile". Artículo recibido el 3 de marzo de 2016, aceptado el 26 de mayo de 2016 y corregido el 23 de junio de 2016.
}

\footnotetext{
2 Departamento de Urbanismo, Universidad de Chile (Chile). E-mail: jinzulza@uchilefau.cl

3 Becario Post-doctoral CONICET/ Universidad de Buenos Aires (Argentina). E-mail: ibandipar@gmail.com
} 
Una de las pautas generalizables del urbanismo posterior a la década de los setenta ha sido la reinversión y revalorización de la ciudad consolidada, con un claro precedente en la renovación urbana funcionalista, aunque con unos efectos aparentemente menos destructivos. La expansión de estas dinámicas, a pesar de su carácter extremadamente diverso, alcanza la casi totalidad del mundo urbano occidental. En el caso de América Latina, la academia ha mostrado atención a este fenómeno desde el discurso del regreso a la ciudad construida (Carrión, 2012; Rojas, 2004) y desde los debates centrados en los procesos de gentrificación (Inzulza-Contardo, 2012; Díaz, 2015; Janoschka et al., 2013; Contreras, 2011). En muchos de estos procesos, que invariablemente implican un periodo de declive y degradación pronunciado y una posterior revalorización de los sectores centrales, los eventos catastróficos puntuales parecen haber jugado un papel relevante. En este sentido, es evidente el interés para las políticas públicas de la relación de este tipo de fenómenos con la renovación urbana y con las transformaciones socioespaciales de la ciudad.

El presente artículo se propone analizar el rol que juegan los fenómenos catastróficos naturales como terremotos, maremotos e inundaciones, dentro de los procesos de declive y gentrificación contemporánea, prestando atención a las estrategias políticas y económicas de diversos agentes. Las preguntas de las que se parte son las siguientes: ¿Qué papel pueden jugar los desastres naturales en los procesos de desvalorización y revalorización de la ciudad construida? ¿De qué forma pueden instrumentalizarse los procesos de reconstrucción asociados a los desastres naturales en función del hipotético objetivo de gentrificar un área? ¿En qué medida la relación entre desastres naturales y gentrificación puede ser generalizable? La hipótesis que aquí se defiende afirma que los eventos catastróficos naturales se han convertido en una oportunidad para los agentes de la producción de ciudad a la hora de implementar grandes programas de redesarrollo en áreas urbanas centrales, siguiendo una lógica capitalista de destrucción creativa y teniendo la gentrificación como consecuencia socioespacial probable.

La anterior proposición se contrasta con la experiencia de tres casos: Ciudad de México (México), Sevilla (España), y Talca (Chile), cada uno de los cuales responde a investigaciones independientes, desarrolladas a lo largo de los últimos diez años. Sevilla resulta un caso paradigmático de renovación de áreas centrales y gentrificación en el Mediterráneo europeo, mientras podría decirse lo mismo para el caso de México para el contexto de las grandes ciudades latinoamericanas. Las conexiones culturales entre ambos casos, que cuentan con centros históricos de grandes dimensiones, con un gran acervo patrimonial y continuados procesos de deterioro durante el siglo XX, hace interesante su comparación (Díaz, 2014) a pesar de las diferencias de escala. Un debate académico desarrollado en la Universidad de Talca en 2015 (Conferencia y taller Internacional Gentrificación en reconstrucción de ciudades intermedias globales) permitió comprar estos dos casos con el proceso reciente de renovación del área central de Talca, a raíz del terremoto de 2013, lo que da lugar al presente texto.

El artículo se compone de tres partes principales. En una primera parte, se desarrolla la discusión teórica, donde se ligan los conceptos claves de desastres naturales, destrucción creativa y gentrificación en el marco de los procesos de desarrollo urbano. La segunda parte expone tres estudios de caso sobre el impacto urbanístico y socioespacial de fenómenos catastróficos. En la tercera parte se realiza una comparación de los casos identificando la lógica subyacente. Dentro de los principales hallazgos, se sugiere que los acontecimientos catastróficos son claves para la eliminación de barreras a nuevas rondas de inversión de capital en entorno construido y que conducen, bajo criterios de mercado, a la gentrificación de las áreas centrales. Finalmente, se entregan las conclusiones del trabajo que invitan a tomar las políticas urbanas y los desastres naturales como parte de la misma agenda política, contemplando los procesos reconstrucción y las dinámicas sociales asociadas a estos. 


\section{Destrucción creativa, rent gap y política urbana}

David Harvey hizo en su momento avances muy notables desarrollando la idea lefebvriana de la inversión de capital en entorno construido como un circuito secundario del capital. La creación de configuraciones espaciales y la circulación del capital en el entorno construido resultarían cada vez más importante a la hora de absorber los excedentes de capital en el sector productivo. Al mismo tiempo la inversión en entorno construido, con su carácter inmóvil, generaría obstáculos de cara a nuevas rondas de inversión. El creciente peso del capital fijo y el fondo de consumo provocarían que la circulación del capital se encontrase progresivamente aprisionada en estructuras físicas inmóviles, dispuestas para tipos particulares de producción y consumo. La necesidad de transformar estas estructuras para adaptarlas a las nuevas necesidades del sistema productivo y permitir nuevas oleadas de inversión en el entorno construido puede dar lugar a procesos dramáticos de devaluación y reestructuración, una de cuyas principales manifestaciones son las crisis económicas (Harvey, 1982 y 1985).

Este tipo de fenómenos destructivos, que liberan el capital de sus ataduras geográficas, se identifican con la lógica de la destrucción creativa, formulación inicial de Schumpeter (1998), cuyo origen tanto Harvey (1990) como Berman (2011) encuentran en el Manifiesto Comunista de Marx y Engels, con su inspirada descripción del carácter revolucionario de la sociedad burguesa. Dicha lógica Ilegaría ser una característica consustancial del capitalismo, como sistema social en permanente cambio, donde las leyes de la competencia coercitivas Ilevan a la producción sistemática de nuevos deseos y necesidades. "En suma, el capitalismo es un sistema social que internaliza reglas destinadas a garantizar su permanencia como fuerza revolucionaria y de ruptura dentro de su propia historia mundial" (Harvey, 1990: 126-127). En términos similares, Berman, en su relectura del Manifiesto Comunista, caracteriza el capitalismo como un sistema en el que todo lo que se construye está hecho para ser destruido, reciclado o reemplazado en un lapso de tiempo breve. Tanto los edificios como las comunidades producidas por la industria capitalista nacen para ser efímeras, temporales, provisionales y construidas para la obsolescencia (Berman, 2011: 95-100).

El caso más conocido de uso de esta lógica para explicar transformaciones urbanas es quizás el influyente estudio de Harvey (2008) sobre la reforma de París por Haussmann, donde la reforma de la ciudad habría servido para eludir temporalmente los problemas de sobreacumulación de capital y devaluación. La apertura de nuevas vías, el derribo de barrios insalubres y el desplazamiento de las clases populares es presentada como un episodio catastrófico que podría haber sido fruto de una guerra o un terremoto. "Al lado del resplandor, los escombros: las ruinas de una decena de barrios céntricos -los barrios más antiguos, oscuros, densos, ruinosos y aterradores de la ciudad, el hogar de decenas de miles de parisienses- arrasados. ¿Adónde irían esas personas? (...)" (Berman, 2011: 152). Al mismo tiempo, el resultado es uno de los centros comerciales históricos más famosos y visitados del mundo que se erige en símbolo de la modernidad y del siglo XIX.

Algunos autores han utilizado la idea de destrucción creativa, recurriendo principalmente a los textos de Harvey, para explicar transformaciones recientes en ciudades latinoamericanas. Marcuse et al. (2014) analizan el uso estratégico del vaciamiento y la destrucción creativa como instrumento para erradicar usos "ilegítimos" (cartoneros, huertas y asentamientos), opuestos a los usos legítimos (rentables económicamente). La destrucción creativa opera aquí para convertir espacios sociales en espacios vacíos, eliminando obstáculos a la inversión del capital. En este sentido, la destrucción creativa se basa en la "acumulación por desvalorización: que consiste en un proceso de destrucción del valor económico de un espacio para una posterior obtención de beneficios mediante la revalorización inmobiliaria" (Marcus et al., 2014: 78). Por su lado, López-Morales (2012) toma la destrucción creativa como un proceso que, desde el punto de vista de las dinámicas del capital, implica la devaluación y posterior reinversión del entorno construido, mientras que desde el punto de vista de la historia urbana supone la producción y destrucción de las áreas urbanas centrales o pericentrales y lo vincula a lo que entiende son procesos de gentrificación en Santiago de Chile (López- 
Morales, 2012: 42). Los ciclos de devaluación y revalorización del capital invertido en entorno construido son la base del acercamiento de Neil Smith (1996) a la gentrificación.

El planteamiento de Smith persigue explicar el proceso histórico de desvalorización del capital en las zonas urbanas deprimidas y la forma en que esta genera la posibilidad de una reinversión rentable. Detrás de este proceso se encontraría la búsqueda de un mayor retorno en las inversiones de capital. Según Smith, la desvalorización sostenida de un barrio puede deberse a tres motivos: mejoras en la productividad (que permiten producir las mismas estructuras a un valor más bajo), obsolescencia de estilo y deterioro físico. Este último aparece de forma inevitable con el paso del tiempo y solo puede corregirse mediante nuevas inversiones. La desvalorización produce un descenso del precio en relación con las viviendas nuevas que suele acompañarse de un filtrado hacia grupos con menor poder adquisitivo. En las áreas centrales de muchas ciudades, ante el declive inminente de los mismos y la aparición de nuevas oportunidades de inversión, los capitales privados fluirían hacia los frentes de expansión urbana, acelerando la desinversión. Por otro lado, Smith explica la revalorización de estos sectores a partir de la existencia de una diferencia suficiente entre la renta efectivamente capitalizada por la propiedad y la renta potencial ante un eventual uso más rentable, el archiconocido rent gap o diferencia potencial de renta que convertiría la reinversión en una respuesta racional del mercado. Dentro de este esquema de devaluación y revalorización, los acontecimientos catastróficos de diversa índole pueden tener diferentes efectos. El más evidente es la capacidad de acelerar la devaluación del capital invertido en el entorno construido. En la medida en que estas estructuras obsoletas se han convertido en barreras a la circulación del capital en entorno construido, los desastres también aceleran las rondas de inversión en este circuito alternativo.

Los riesgos de la teoría del rent gap son, en primer lugar, la tentación de caer en un cierto mecanicismo, como si medir este escalón permitiera identificar las zonas donde se está produciendo o va a producirse la gentrificación: "Una vez que la diferencia po- tencial de renta es lo suficientemente grande, se inicia la gentrificación en un barrio determinado" (Smith, 1996: 127), algo que parece improbable ante la experiencia empírica acumulada en las últimas décadas sobre estos procesos. La especulación y la búsqueda del máximo beneficio tras la formación de rent gaps, sin duda, juegan un papel en la gentrificación, pero una relación directa e inevitable entre gentrificación y rent gap es mucho más cuestionable. En segundo lugar, Smith parece conceder poco peso al estado como agente. En su explicación, este puede jugar un papel mediante medidas regulatorias y subsidios, aunque su atención se dirige a las dinámicas del mercado y tiende a dar más importancia a la voluntad de promotores e instituciones financieras. Sin embargo, la experiencia latinoamericana otorga un rol mucho más protagónico al Estado en la concepción y desarrollo de estrategias de revalorización de sectores degradados.

El propio Neil Smith Ilamó la atención sobre la progresiva importancia de las estrategias desarrolladas desde la agencia del estado en un periodo más reciente (Hackword \& Smith, 2001). En el contexto neoliberal, la intervención estatal en materia de ordenación urbana más que haber perdido peso ha modificado su orientación. Los objetivos de redistribución o equilibrio territorial habrían tendido a perder peso en las agendas políticas, en favor de un uso estratégico de nuevos proyectos y lugares potencialmente competitivos (Brenner, 2004). Dentro de esta orientación, las operaciones de renovación urbana sobre áreas consolidadas pero con usos poco rentables, considerados obsoletos, se han vuelto algunas de las estrategias más comunes para impulsar la economía urbana (Harvey, 2003). La proliferación de intervenciones sobre la ciudad construida en América Latina y otras regiones del mundo, especialmente en áreas progresivamente centrales y con cierta carga patrimonial, identificadas como procesos de gentrificación, se enmarcan en este tipo de estrategias (Delgadillo et al., 2015). El rol de los eventos catastróficos dentro de este tipo de estrategias de marketing urbano y renovación es una cuestión relevante que no ha sido tratada en profundidad, con escasas excepciones. Por ejemplo, los estudios sobre Chile de Inzulza-Contardo (2014) apuntan la manera en que los terremotos se han convertido en 
una oportunidad para los inversores privados a la hora de implementar grandes programas de redesarrollo en áreas urbanas centrales.

La cuestión del desarrollo urbano postterremoto ha tendido a entenderse como una respuesta a la reducción repentina del stock de vivienda (MINVU, 2013) y a la eliminación de servicios básicos (suministro de agua, electricidad, conectividad primaria, etc.). Solo algunos casos han tenido en cuenta las consecuencias socioeconómicas y culturales para las comunidades afectadas, incorporando marcos de acción de planificación estratégica a corto, mediano y largo plazo para confrontar terremotos (PNUD, 2010b y 2004). Dentro de este contexto, algunas buenas prácticas tales como el reporte de la República de Indonesia y el plan maestro de reconstrucción de Skopje (Lozanovksa, 2012) muestran cómo los gobiernos nacionales y locales pueden incluir además la reconstrucción de la comunidad, su economía de escala, infraestrucura y formas de gobernanza apropiadas. Sin embargo, las políticas urbanas y los desastres naturales solo parecen ser parte de la misma agenda política en la medida en que los segundos ofrecen una oportunidad para adaptar las ciudades a las necesidades de circulación del capital en el entorno construido.

Siguiendo una línea de análisis crítico de las estrategias del urbanismo neoliberal, este trabajo pretende aportar al conocimiento de la relación entre procesos recientes de gentri- ficación y catástrofes naturales, señalando el potencial uso estratégico de estos últimos por parte de la política urbana siguiendo la lógica capitalista de la destrucción creativa.

\section{Desastres naturales y renovación urbana en las áreas centrales de Sevilla, México y Talca}

En vista de las investigaciones realizadas hasta la fecha, parece que los desastres naturales pueden afectar de forma diversa a la gentrificación. En primer lugar, los acontecimientos catastróficos podrían ser clave en la desvalorización de los espacios centrales, que permite la creación de ganancias especulativas en su revalorización posterior. En segundo lugar, los desastres naturales suponen un foco en sí mismo de desplazamiento de población tradicional de las áreas centrales. Por último, en la medida en que facilita procesos posteriores de renovación urbana. A continuación se tratan estos aspectos para el caso de las ciudades de Sevilla, Ciudad de México y Talca, atendiendo a las transformaciones de sus respectivas áreas centrales (Figura $\mathrm{N}^{\circ} 1$ ). La reconstrucción histórica de los casos permitirá ilustrar la relación de los fenómenos catastróficos con la gentrificación a través de la lógica de la destrucción creativa, que se ha establecido en el epígrafe anterior de forma teórica. Una relación que no se habría tenido en cuenta suficientemente hasta ahora. 
Figura $\mathrm{N}^{\circ} 1$

Distrito central de la Ciudad de México y centros históricos de Sevilla y Talca

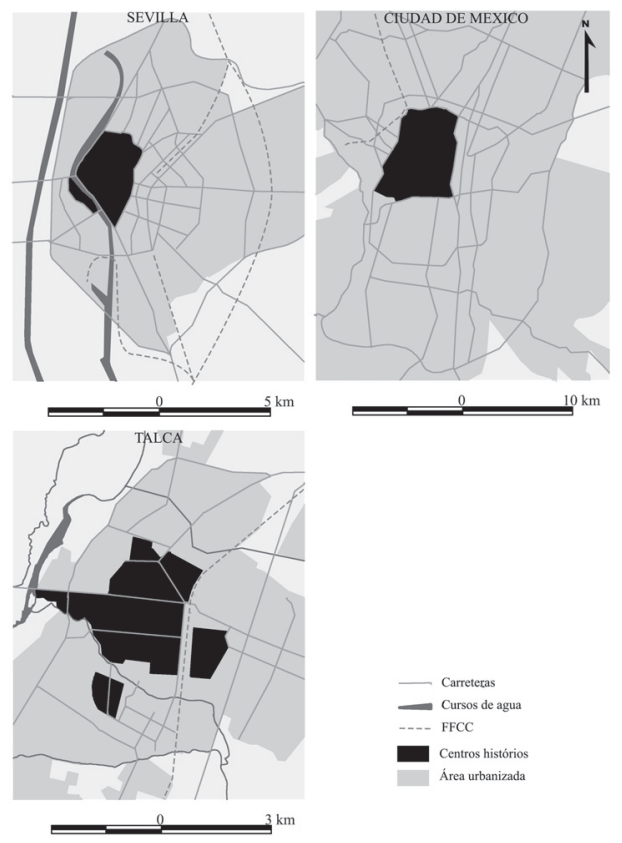

Fuente: Elaboración propia a partir de Open Maps.

El análisis se fundamenta en su mayor parte sobre fuentes secundarias, entre las que se incluyen un buen número de trabajos desarrollados por los autores de este texto. Los ejemplos, implican una notable diversidad en cuanto a escalas (Cuadro $N^{\circ} 1$ ) y tiempos (respecto del desarrollo de los acontecimientos catastróficos y posterior rehabilitación). Esta diversidad permite distinguir elementos generalizables a las lógicas del urbanismo capitalista y aspectos contingentes fruto de la particularidad de cada urbe para la relación entre el acontecimiento catastrófico y los procesos urbanos (caso histórico comparado por similitud, siguiendo la tipificación de Coller, 2005: 44-45). Se realiza la comparación atendiendo a una estructura aconsejada por la situación actual del debate en torno a la gentrificación. Se analizan en este sentido, los siguientes aspectos: desvalorización y revalorización del espacio centrales de la ciudad, desplazamiento y destrucción de infraestructuras provocadas por los acontecimientos catastróficos y relación con operaciones de renovación urbana.

Cuadro $\mathrm{N}^{\circ} 1$

Crecimiento de la población

\begin{tabular}{|l|r|r|r|r|r|r|}
\hline & \multicolumn{1}{|c|}{1960} & \multicolumn{1}{c|}{1970} & \multicolumn{1}{c|}{1980} & \multicolumn{1}{c|}{1990} & \multicolumn{1}{c|}{2000} & \multicolumn{1}{c|}{2010} \\
\hline Ciudad de México & 4.870 .876 & 6.874 .165 & 8.831 .079 & 8.235 .744 & 8.605 .239 & 8.851 .080 \\
\hline Sevilla* & 442.300 & 548.072 & 653.833 & 704.857 & 684.633 & 703.021 \\
\hline Talca** & 68.148 & 94.449 & 128.544 & 159.711 & 189.505 & 253.742 \\
\hline
\end{tabular}

*A partir de 1980 los datos del censo responden a los años acabados en uno: 1981, 1991, 2001 y2011.

**A partir de 1980, los datos del censo corresponden a los años acabados en dos: 1982, 1992, 2002 y 2012. Fuente: Censos de Población y Vivienda, INEGI, INE-España e INE-Chile. 


\section{La inundación (riada) de 1961 en Sevilla, España}

Sevilla resulta un caso paradigmático reciente de transformación radical de un centro histórico de gran tamaño, implicando contundentes procesos de gentrificación e indicios claros de desplazamiento de las clases populares. Si bien las investigaciones sobre el caso han tendido a centrarse en las políticas de renovación urbana y valorización del patrimonio más recientes (Díaz, 2011), una profundización en el caso histórico invita a situar el origen de estos procesos mucho más atrás, en relación a la riada de 1961, que ha sido una referencia clave en la evolución urbana posterior de la ciudad.

En noviembre de 1961, como consecuencia del desbordamiento del arroyo TamarguiIlo, afluente del Guadalquivir, la ciudad de Sevilla sufre su inundación de mayor magnitud (Díaz del Olmo y Almoguerra, 2014). La ciudad contaba en este momento con algo menos de medio millón de habitantes. Tres cuartas partes de la capital se inundaron con más de cuatro millones de metros cúbicos de agua, tras un día de lluvias y la rotura del muro de defensa del arroyo (Figura $\mathrm{N}^{\circ} 2$ ). La población afectada alcanzó las 125.000 personas, 30.176 quedaron sin hogar, 4.127 viviendas fueron invadidas por el agua, 1.603 vivienda precarias (o chabolas) quedaron destruidas y 1.228 edificios sufrieron graves daños. Los informes técnicos posteriores señalarían la existencia de 13.043 viviendas en mal estado que necesitaron evacuación inmediata, a las que se añadían 16.343 viviendas en estado totalmente insalubre sobre las que se proyectaba la evacuación de sus vecinos (Florez, 2011; Castillo, 2013).

La segregación socioespacial de la ciudad de Sevilla está muy vinculada a la altura del terreno $y$, por lo tanto, a su sensibilidad ante posibles inundaciones, por lo que las zonas más afectadas fueron en primer lugar, los barrios populares. La crecida barrió con el cinturón de chabolas que se había conformado alrededor de la ciudad entre la Guerra Civil Española y la década de los años 60 , formado por una treintena de núcleos construidos con materiales de baja calidad y que tomaban pre- cisamente las ubicaciones más vulnerables a las crecidas del río y sus afluentes. Dentro del área histórica, el centro sur, con las cotas más altas, concentraba la residencia burguesa, el centro financiero y los edificios de representación del poder político y religioso. La zona norte, con las cotas más bajas, era donde se concentraban en mayor medida las viviendas colectivas en alquiler para clases populares, allí denominados corrales de vecinos. Dentro de este sector, la Alameda de Hércules se ubicaba sobre uno de los antiguos brazos de del Guadalquivir y era el corazón de la SeviIla obrera. Esta zona estuvo tres días bajo las aguas y la altura llegó a 1,80 metro.

Los corrales de vecinos, que venían de un proceso de descapitalización y abandono asociado a las operaciones de ensanche de la ciudad, se derrumbaron o aceleraron su deterioro. Aproximadamente la mitad de los edificios del centro histórico se encontraban en este momento en situación ruinosa. Como resultado, la migración desde los barrios populares del centro histórico siguió una ruta desde los corrales destruidos o semiderruidos a los albergues municipales. Desde estos alojamientos provisionales, el siguiente paso fueron las grandes intervenciones de vivienda de promoción pública de estilo funcionalista, en España comúnmente denominadas polígonos de vivienda, con una ubicación marcadamente periférica (González Dorado, 1975, Marín de Terán, 1980). Posteriormente, en los años 70 fueron trasladados primero a refugios y después a nuevos hogares construidos por el Estado cerca de veinte mil familias, la mayoría provocados por el mal estado de las edificaciones. El gobernador civil Utrera Molina afirmaría que a raíz de la inundación "Una población de cien mil personas, en una ciudad de medio millón de habitantes, fue trasvasada desde la injusticia del corral a la dignidad del piso sindical" (Castillo, 2013: 56). De esta forma, respecto del área central, marcadamente popular en este momento, la riada implica una aceleración de la desvalorización de las estructuras físicas, un incentivo del capital inmobiliario a la inversión en la construcción de la periferia urbana de la ciudad y el inicio contundente del desplazamiento de los grupos de bajos ingresos fuera del área central, algo que continuaría en las décadas posteriores. 
Figura $\mathrm{N}^{\circ} 2$

Inundación de una calle de Sevilla en 1961

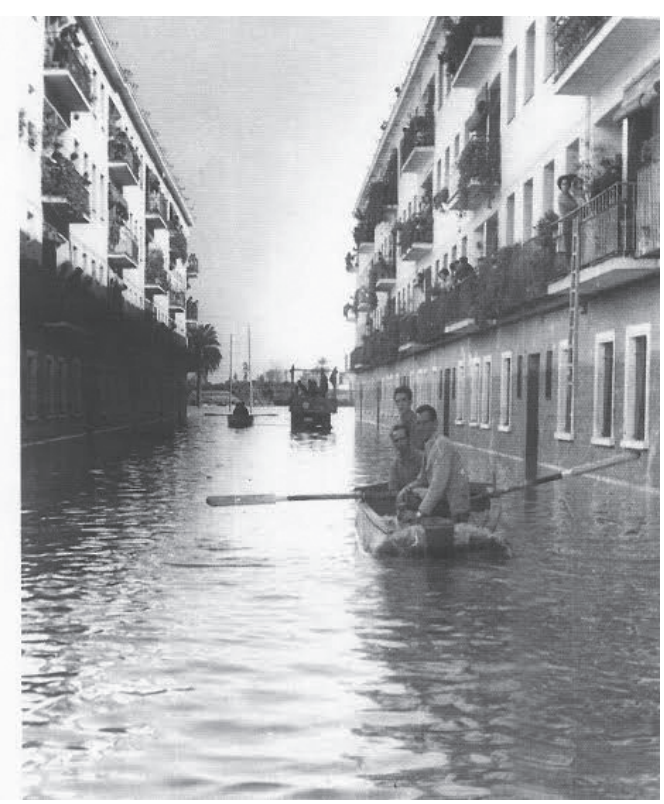

Fuente: Archivo personal de los autores.

Por otro lado, la inundación facilitó el desarrollo de operaciones de renovación urbana de tabula rasa en la década de 1970, justificando la necesidad de intervención y eliminando los obstáculos más evidentes a la misma: la población y las estructuras obsoletas. En el extremo sur del arrabal de Triana ya se habían realizado con anterioridad y se intensificaron a raíz del destrozo provocado por la inundación (Ruiz, 2005). En el centro histórico, se redesarrolló gran parte del cuadrante noreste, mediante expropiaciones forzosas. Los corrales de vecinos y las viviendas arruinadas fueron sustituidos por un conjunto de bloques desiguales que supone una primera introducción de clases profesionales en la zona, mientras la dinámica de expulsión de población popular a las viviendas periféricas construidas por el Estado continuaba (Cardoso, 1983). No obstante, al mismo tiempo, dentro de esta operación, se realizaron algunos de los primeros proyectos de reubicación in situ de la población popular, financiados por el Estado, en edificaciones funcionalistas que se mantienen hasta la actualidad.

Otros planes de este tipo, como el Plan Especial de Renovación Urbana de la Alameda de Hércules de 1977, que planteaba la sustitución radical de una parte importante de la edificación, no llegaron a realizarse. Otro obstáculo, esta vez de carácter político-regulatorio, se levantó contra las nuevas rondas de inversión de capital en el área central. Las políticas proteccionistas con el patrimonio de los años ochenta frenaron este tipo de planes, de tal forma que el lento declive de la zona se prolongó hasta la celebración de la Exposición Universal de 1992. Tanto los documentos técnicos como la prensa de la época responsabilizaban en gran medida a la protección del patrimonio del continuado deterioro de la zona histórica, que además reunía una gran parte de los atractivos turísticos de la ciudad. El siguiente extracto de un artículo de opinión del periódico $A B C$, pertenece a un conocido escritor sevillano:

“[...] la Alameda de Hércules se ha convertido en uno de los símbolos de la antisevilla, cuando debía ser todo lo contrario; es decir, cuando esta magnífica alameda podría ser el gran paseo céntrico de la Sevilla del noventa y dos [...] ésta será la Sevilla que encontrarán los turistas que nos visiten." (ABC, 23-4-1990, citado en Díaz, 2011). 
Las fuertes expectativas sobre la Expo 92, en un contexto de auge del sector inmobiliario, provocaron un cambio hacia una política más permisiva con los constructores en cuanto a la obtención de licencias (especialmente declaraciones de ruina, que permitían el ulterior derribo y reconstrucción), y en general fueron orientando el planeamiento hacia un cierto pragmatismo neoliberal, centrado en la promoción de la iniciativa privada y en proyectos e inversiones públicas puntuales. El norte del centro histórico, la zona histórica degradada más extensa, necesitaría de varios planes específicos que se desarrollarían fundamentalmente durante la segunda mitad de los años noventa. En el corazón de esta área se llevó a cabo la mayor operación de renovación urbana tras la de San Julián, implicando la apertura de nuevas calles, agregación de parcelas, derribos y levantamiento de nuevos edificios destinados a clases medias. La puesta en valor de la zona vendría acompañada por un Plan Urban, con fondos de la Unión Europea, que permitirían la remodelación de varios edificios históricos con fines públicos y la reurbanización completa del sector, calles y plazas públicas. A estos les seguirían un nuevo plan de remodelación de la Alameda de Hércules ya en la primera década del siglo XXI.

García Jaén (1998) autora del Plan Urban para la zona señalaba que la prometida inversión social había sido menos de lo esperado y que, por el contrario, se había producido una revalorización enorme del sector y la entrada en tromba de capitales privados. En el contexto de revalorización del área por recapitalización de origen público, habrían proliferado las empresas que compraban edificios de viviendas colectivas a propietarios sin recursos suficientes como para enfrentar la rehabilitación, a menudo venidas de fuera de la ciudad. Muchas de estas viviendas se compraban con algunos de sus últimos arrendatarios, a los que en el gobierno local y entre los promotores inmobiliarios tendía a calificarse de "bichos". La connivencia de la administración con los promotores tuvo como principal resultado la proliferación de declaraciones de ruina, que permitían el desalojo de los arrendatarios y el derribo de la edificación, que era sustituida por nuevos departamentos para clases medias o al menos para cierta demanda solvente (Díaz, 2011).
Esta última oleada de demoliciones, desplazamiento y reinversión vino permitida por las mismas condiciones que habían facilitado las operaciones de renovación anteriores. Las deterioradas viviendas colectivas que fueron refuncionalizadas Ilevaban mucho tiempo siendo vaciadas, quedaba poca población y muy envejecida, además de carácter humilde y con escasa capacidad de organización. Aun así, la insistencia de los movimientos sociales de la ciudad y el cambio de gobierno en 2003 hacia una coalición de izquierda permitió poner límites a los derribos y desarrollar algunas iniciativas contra el abuso de los promotores, como la expropiación de varios edificios de viviendas colectivas para su dedicación a el realojo de inquilinos desahuciados y sin recursos (Díaz, 2012).

\section{El terremoto de 1985 en Ciudad de México, México}

En comparación con casos como el de Sevilla, la gentrificación del área central de la Ciudad de México ha resultado un proceso de éxito mucho más matizable (Díaz, 2014). A pesar de la sucesión de planes en las últimas décadas y la intensidad de la inversión privada y pública, gran parte del área histórica de la ciudad sigue siendo evidentemente popular, al mismo tiempo que otra parte ha sido radicalmente transformada. De nuevo, un examen detallado del caso histórico invita a plantear tanto las raíces de la transformación como algunos de los obstáculos clave a la valorización de estas áreas centrales a partir del terremoto de 1985.

En Ciudad de México, el 19 de septiembre de 1985 se produjo un terremoto de 8,1 Mw, seguido un día después por otro sismo de intensidad algo menor. La diversidad de la enorme cantidad de terreno ocupada por la mancha urbana de la ciudad hizo que mientras determinadas zonas permanecieron intactas, en otras la devastación fuese casi completa. El fenómeno sísmico afectó principalmente a las zonas centrales ubicadas sobre suelos arcillosos, el centro histórico y los barrios históricos en su derredor (Figura $N^{\circ}$ 3). Se contabilizaron 5.727 edificios dañados, 3.800 de ellos edificios de viviendas. Los casos de derrumbes y colapso de edificios fueron múltiples y, como resultado, hubo 
entre 8.000 y 10.000 muertos. Es difícil calcular el número de viviendas afectadas, los efectos sobre las vecindades fueron menos espectaculares y pasaron más desapercibidos que el derrumbe de los grandes edificios del sector financiero. No obstante, extensas zonas habitacionales populares quedaron afectadas. Como consecuencia, proliferaron los campamentos provisionales, muchos de ellos ubicados en los solares de los derrumbes, encontrándose todavía activos un número considerable de ellos, o en plena calle, de donde fueron desapareciendo muy paulatinamente. El gobierno reconoció un cuarto de millón de afectados (Ducci, 2014).

Aquí, de nuevo, la intervención de corte funcionalista adoptó una función redistributiva, en un marco preneoliberal, coincidiendo además con el auge de los discursos de protección del patrimonio. Como resultado se llevó a cabo una intervención excepcionalmente social. El programa de Renovación Habitacional Popular, entre 1985 y 1987, reconstruyó 48 mil viviendas sobre poco más de tres mil predios expropiados. Nunca una ciudad latinoamericana había expropiado tantos predios para reconstruir miles de viviendas y destinarlas a la población de extracción popular para un realojo en el propio centro. Los programas de Renovación Habitación Popular reconstruyeron viviendas en conjuntos habitacionales pequeños y medianos para restituir la vivienda a quienes la perdieron en los sismos. También inmuebles de tipologías edilicias antiguas dañados fueron objeto de rehabilitación manteniendo a la población original (Duhau, 1987, Delgadillo, 2012). Esta política guarda relación con la existencia de un fuerte movimiento vecinal, que procedía de las décadas anteriores pero que alcanzó su máxima influencia precisamente a partir de la catástrofe y de las reacciones de autoorganización y solidaridad que se produjeron en la población. También es cierto que, como señala Delgadillo (2012), la mayor parte de las expropiaciones se ubicaron el área pericentral y en los barrios menos valorados, al norte y al este, con escaso impacto en la cuadrícula central, Patrimonio de la Humanidad y espacio que se tornaría muy cotizado en las décadas siguientes.

Figura $\mathrm{N}^{\circ} 3$

Daños en Ciudad de México, 1985

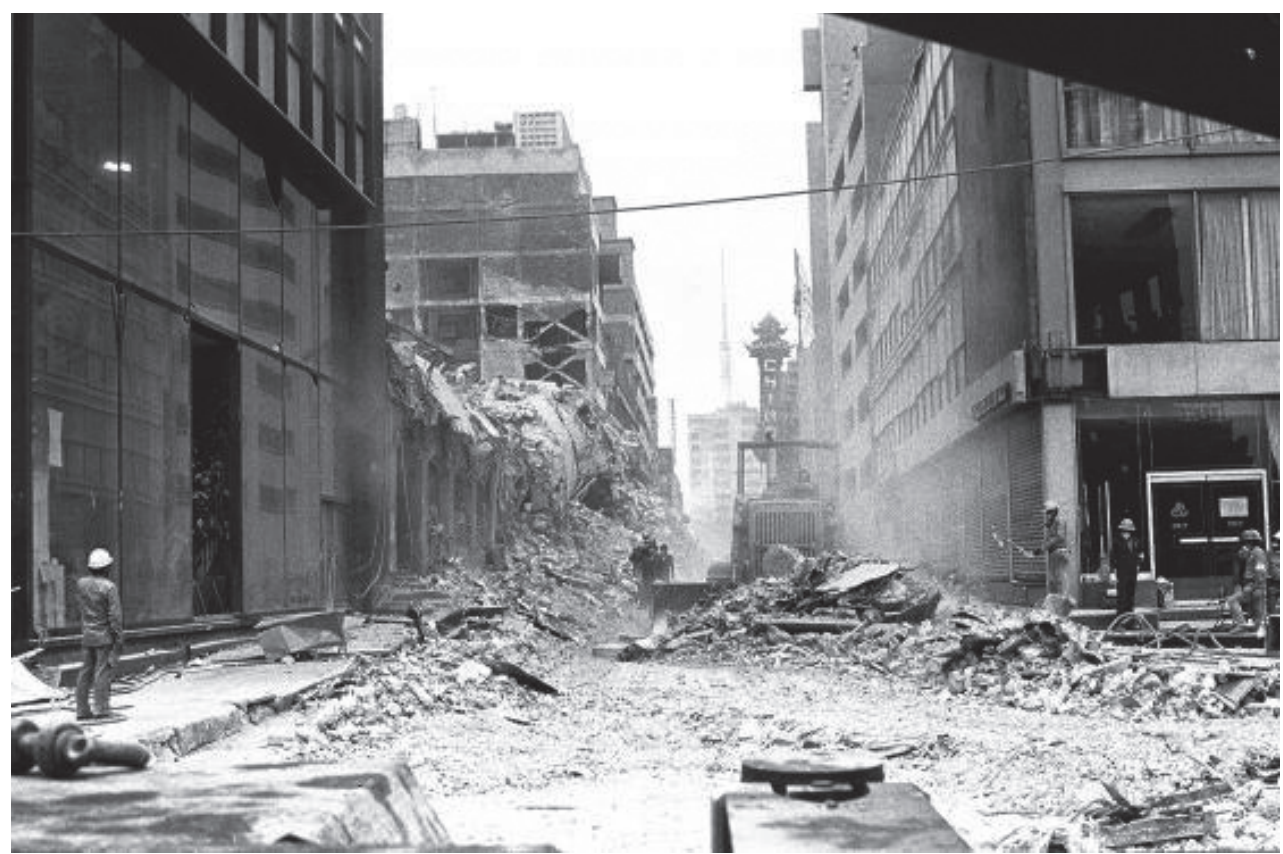

Fuente: El Universal, disponible en Internet: http://www.unioncancun.mx/articulo/2014/09/19/ 
A pesar de la intervención en vivienda social, el terremoto mantuvo el efecto de acelerar procesos de deterioro previo del entorno construido y de vaciamiento demográfico. El centro histórico venía siendo descapitalizado en favor de las áreas de expansión al suroeste desde principios del siglo XX y desde los años 50 había empezado a perder población. La degradación previa de las estructuras y la destrucción de las vecindades se tornó en el contexto del terremoto en edificios derrumbados y en un incremento de las situaciones ruinosas y los solares. Muchos edificios se perdieron en este contexto y la degradación del entorno se aceleró notablemente. Además, la precariedad en la construcción y la falta de mantenimiento de las nuevas viviendas sociales hicieron que en muchos casos se deteriorasen rápidamente. La fuga de población, especialmente de aquella con cierto poder adquisitivo, se aceleró, a pesar de que también se incrementó el fenómeno de la ocupación de predios por parte de grupos populares. En 1990 las viviendas en arrendamiento eran un $42 \%$ y la principal función del centro histórico la residencial, seguida por las bodegas. Existían asimismo "cerca de 300 predios, ocupados por alrededor de 2.600 familias, que se encontraban vinculadas a distintas organizaciones sociales constituidas en demandantes de vivienda" (PDI-CHCM, 2000: 27). El $30 \%$ de la población del área central habitaba en vecindades, un $11 \%$ del parque habitacional contaba con baños comunes y para 1997 un 9\% de la población que alquilaba su vivienda enfrentaba un juicio de desalojo. En los noventa, el centro seguía siendo el principal destino de la inmigración rural en una primera fase de llegada, acogiendo además una gran cantidad de personas sin techo, incluidos niños en situación de calle y prostitución (PDI-CHCM, 2000: 38-40).

En la década de los noventa, muchos de los líderes de las organizaciones vecinales que habían surgido a raíz del terremoto habían ido entrando en el gobierno de Ciudad de México y en especial al Instituto de Vivienda (INVI), manteniendo en gran parte la orientación social de las políticas locales de vivienda. A esto se le suma una fuerte vigilancia del patrimonio histórico por parte del Instituto Nacional de Antropología e Historia (INAH) que mantenía un control férreo sobre la actividad constructora el centro histórico, con una política conservacionista que no facilitaba los emprendimientos privados. Estos elementos regulatorios reforzaban los obstáculos a una renovación urbana del sector basada en las lógicas del mercado. No obstante, desde finales de 1980, de forma similar a Sevilla, se venía produciendo un giro en la política urbana, hacia planteamientos pragmáticos para con la protección del patrimonio y claramente alineados con los intereses del capital privado, siguiendo las propuestas internacionales en política urbana neoliberal (Hiernaux, 1999; Valenzuela, 2013; Iracheta, 1998). En este sentido se desarrollaron diversos programas parciales de desarrollo urbano, incluyendo uno para el Centro Histórico y otro para el contiguo entorno de la Alameda Central. Según el programa urbanístico de la delegación central de la ciudad de 2008: "Puede decirse que paradójicamente, el terremoto de 1985 fue detonador para la Planeación del Desarrollo Urbano, desde el sector público" (GDF, 2008: 14). En 1990, se creó el Patronato del Centro Histórico el cual constituyó el mismo año un Fideicomiso para promover la coordinación de particularidades y autoridades públicas en la regeneración de la zona. Se realizó una política de apoyos y estímulos fiscales, subsidiando impuestos y licencias a los interesados en realizar obras, consiguiendo una fuerte inversión. El Fideicomiso asumió también la función de intermediación entre el proteccionismo del INAH y el pragmatismo de los propietarios, con una política orientada a favorecer la inversión privada y la entrada de residentes y consumidores solventes.

En 2002 el Fideicomiso se constituyó como responsable del Programa para la Rehabilitación del Centro Histórico, marco para instrumentalizar la coordinación entre el Estado y los inversores privados. La Inmobiliaria Centro Histórico de la Ciudad de México y empresas del Grupo Carso (de Carlos Slim, multimillonario y presidente del comité ejecutivo del programa de rescate) adquirieron y rehabilitaron más de 60 edificios, de los cuales 55 albergarían 620 departamentos de uso habitacional (AUTORIDAD del CHCM, 2011). Asimismo, se produjo una inversión pública a fondo perdido de 500 millones de pesos. En el área de recuperación se revalorizó la propiedad privada a través de la inversión en el espacio público y la mejora de fachadas, se reubicaron las actividades dañi- 
nas para la imagen urbana, como el comercio ambulante, y se reforzó la seguridad pública (Delgadillo, 2008).

La renovación urbana con orientación social que se realizó en la década de los 80 , en parte, no solucionó la dinámica de deterioro por tratarse en muchos casos de estructuras de ínfima calidad, con materiales pobres, desarrolladas con la urgencia que merecía la ocasión y que han carecido del necesario seguimiento y mantenimiento por parte del INVI. Muchas de las vecindades rehabilitadas por este organismo, incluso dentro de la cuadrícula central, presentan hoy día un aspecto ruinoso y de tugurio, especialmente aquellas más alejadas de los principales focos de inversión al suroeste. Además, en el contexto de la renovación se produjo el desalojo de muchos de los edificios ocupados, pero también de edificios de titularidad pública en situación inhabitable. En la renovación más reciente, una parte de los edificios que se renuevan lo hacen sobre edificios anteriormente ocupados irregularmente. La baja densidad del área central, después de décadas de declive demográfico y la irregularidad en la tenencia de muchos edificios han facilitado la actuación de los agentes capitalistas de la renovación urbana a la hora de conseguir predios para reinvertir, al menos en un primer momento. A esto se le suma un evidente desplazamiento de usos, con la expulsión fuera del recinto histórico de la prostitución, los "sintecho" y de una parte del ambulantaje. No obstante, al mismo tiempo que el Fideicomiso intenta atraer residentes de clase media y hay una estrategia de embellecimiento para la atracción de visitantes y turistas, el INVI y otras instituciones del gobierno de Ciudad de México siguen construyendo vivienda pública y realojando población de bajos recursos. La capacidad de los comerciantes para mantenerse en las áreas centrales también ha sido notable. Al mismo tiempo, a pesar de las importantes inversiones vertidas sobre el centro histórico de la ciudad, tanto de capital público como de capital privado, la oferta de viviendas para una demanda solvente sigue siendo escasa y esto se debe en gran parte a la fragmentación de la propiedad que se produjo en el contexto de la renovación urbana posterremoto (Díaz, 2015). De esta forma, la política de reconstrucción posterremoto ha terminado suponiendo un obstáculo difícil de salvar para la renovación urbana en el marco de las políticas neoliberales y para la atracción de residentes con mayor solvencia económica.

\section{El terremoto de 2010 en Talca, Chile}

En contraste con los casos de Ciudad de México y Sevilla, en el caso de Talca el acontecimiento catastrófico se produce en un contexto donde las tendencias neoliberales en materia de política urbanística están plenamente consolidadas. Si en los dos primeros casos, el urbanismo que responde en primer lugar a la catástrofe se sitúa dentro del paradigma funcionalista e intervencionista, en este caso se trata de un urbanismo estratégico y orientado al mercado. Asimismo, el vínculo catástrofe, renovación urbana y sustitución de la población del área central es directo e inmediato, a pesar de lo cual siguen existiendo una lógica común subyacente respecto de los otros dos casos.

En febrero de 2010 un terremoto con una magnitud de 8.8 Mw con su epicentro en el mar, impactó sobre el territorio chileno. Al terremoto le siguió un fuerte tsunami que acabó por destruir varias de las ciudades afectadas. El resultado fueron más de 500 muertos y dos millones de damnificados, aproximadamente el $10 \%$ de la población del país. Talca fue una de las ciudades con mayor daño en vivienda. En esta ciudad, la mayor afección del desastre se produjo en el centro histórico y los 15 barrios fundacionales en torno a él (un 30\% de la superficie urbana), donde la mayor parte de las viviendas fueron destruidas. Según el catastro realizado por el municipio, más del $60 \%$ de las viviendas de este área presentó daños de diversa magnitud. Cerca de 6.000 propiedades presentaban un severo deterioro con al menos 1.700 de ellas en situación ruinosa y unas 2.000 familias quedaron damnificadas, alrededor de 8.457 personas (Inzulza-Contardo, 2014; Cárdenas, 2015). Fuera del área más terciarizada en torno a la plaza central, se trataba de sectores construidos por grupos populares que progresivamente habían ido quedando en una localización privilegiada y céntrica. 
En Talca, el centro histórico se caracterizaba por conservar cierta heterogeneidad respecto de sus habitantes, siendo casi el único lugar de la ciudad donde convivían todos los estratos sociales. No obstante, la mitad de los residentes pertenecía a estratos sociales bajos y un $35 \%$ de las familias eran arrendatarias. Los vecinos eran en muchos casos personas de la tercera edad y jubilados. También existían muchos hogares propietarios con varias generaciones de la misma familia. No obstante, la amenaza de desplazamiento para la población más vulnerable se ha hecho evidente en los últimos años. Debido a la destrucción de las estructuras, el área ha perdido su capacidad de ofrecer viviendas en alquiler, opción residencial que se corresponde con el perfil de habitante más humilde. Además, las familias propietarias que han perdido su vivienda se han visto en posesión de un suelo con elevado valor de cambio al mismo tiempo que con valores de uso muy limitados, lo que supone un gran incentivo para la venta a empresas inmobiliarias.

La reacción frente a la catástrofe comenzó por la construcción de refugios y viviendas prefabricadas provisionales para absorber parte de la población afectada. En términos generales, la política de reconstrucción posterior se orientó fundamentalmente a la producción de nueva vivienda. La reconstrucción se planteó en la línea del planeamiento estratégico, no vinculante, orientado al desarrollo de proyectos puntuales más que a una perspectiva territorial y con una gran dependencia de la voluntad de la iniciativa privada. Así, la reconstrucción a largo plazo se dejó en su mayor parte al mercado inmobiliario, incentivado mediante subsidios directos a los consumidores con menos recursos. Como resultado, las opciones más rentables para los desarrolladores privados en relación al consumidor subsidiado, antiguos inquilinos de las áreas centrales damnificados por el terremoto, han sido la construcción de conjuntos de vivienda social nueva en la periferia, en localizaciones pobres y con infraestructuras y equipamientos insuficientes o inexistentes.

La lógica del mercado hace que no resulte rentable construir en bajas densidades, que son las que permite el centro urbano, para grupos sociales con bajo poder adquisitivo. De esta forma, la mayor parte de la construcción de vivienda incentivada por el terremoto se ha concentrado hasta ahora en la periferia, mientras que la rehabilitación del área central avanza de forma muy lenta. Actualmente se encuentran en construcción 3.000 nuevas viviendas sociales en la periferia de la ciudad. Al mismo tiempo se han inyectado cuarenta millones de dólares para subsidiar la construcción de nueva oferta habitacional en la zona central dirigida a familias con capacidad de endeudamiento, que muchos damnificados no tienen por su condición socioeconómica y/o por su avanzada edad (Inzulza-Contardo, 2014; Rasse y Letelier, 2013). Por otro lado, Letelier y Boyco (2013) han estudiado la creciente movilización vecinal a raíz del terremoto. En el marco del terremoto se han creado Comités Sin Tierra y se ha denunciado el fomento de la expulsión de la población y el aburguesamiento de las zonas afectadas, impulsando soluciones alternativas y de mayor calidad.

Con carácter previo al terremoto de 2010, Rasse y Letelier (2013) detectaban la existencia de una tendencia a la renovación mediante densificación dirigida a estratos más solventes de Talca. Tras el terremoto, se ha hecho evidente en las áreas centrales la irrupción de viviendas de mayor valor, en edificaciones de densidad media, apoyadas por subsidios estatales y aprovechando una percepción de las rentas potenciales al alza. Esto no está totalmente desvinculado de la inversión en infraestructuras y equipamientos en la zona, incluyendo instalaciones hospitalarias o de la Universidad de Talca. La proliferación reciente de viviendas restauradas y condominios cerrados que visiblemente se corresponden a grupos privilegiados Ileva a Rasse y Letelier (2013) e Inzulza-Contardo (2014) a apuntar hacia un incipiente proceso de gentrificación en la zona. Lo que podría haber sido un proceso mucho más penoso y dilatado en el tiempo, de densificación y aburguesamiento, habría sido acelerado por la eliminación de obstáculos y el incentivo a la renovación urbana que supuso el terremoto. 
Figura $\mathrm{N}^{\circ} 4$

Nuevo proyecto de vivienda en Talca, 2014

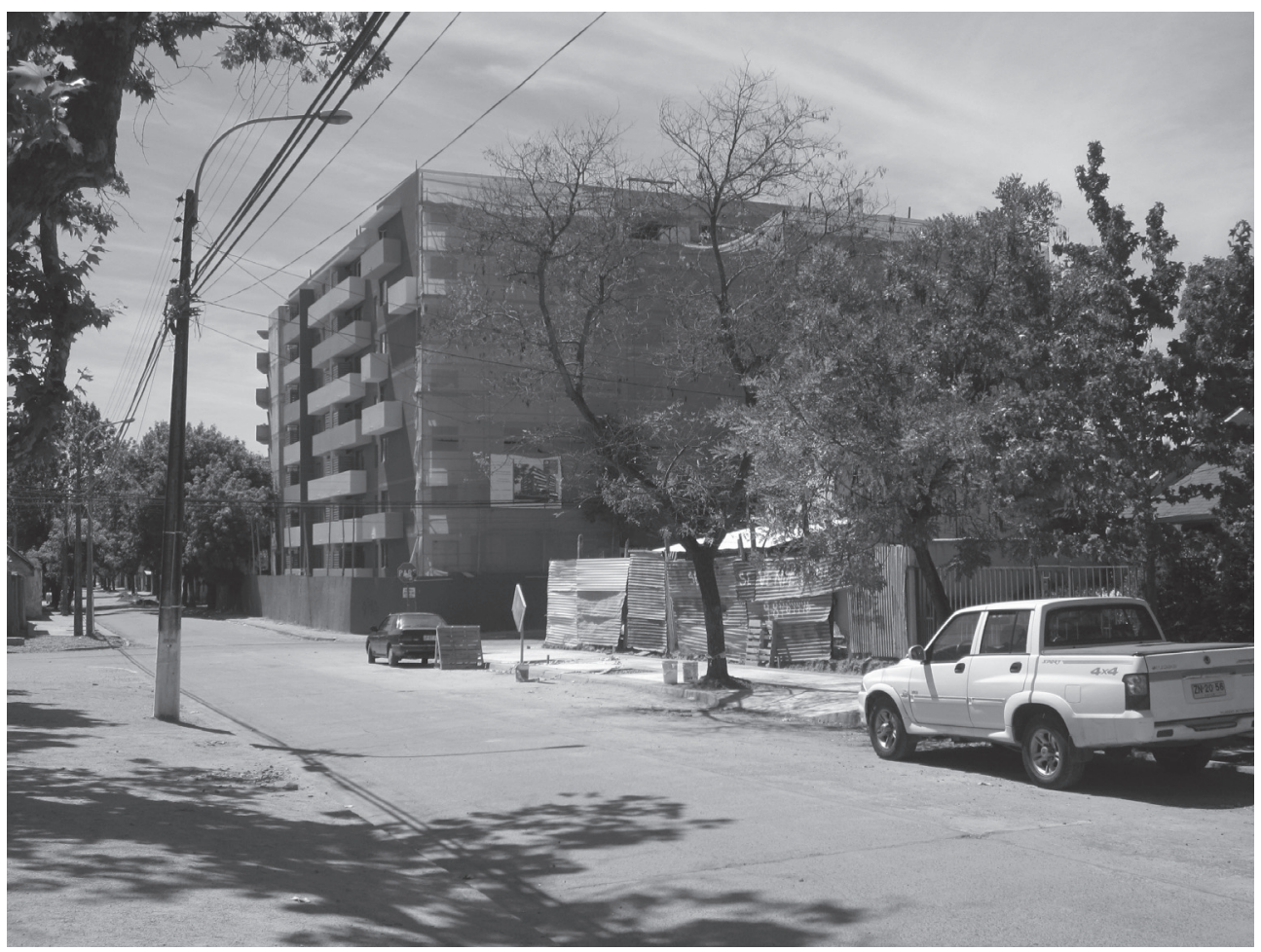

Fuente: Archivo personal de los autores.

Los subsidios han resultado "insuficientes para permitir que los afectados permanecieran en sus barrios de origen, así como también para realizar los arreglos pertinentes a la vivienda con el objetivo de que estas siguieran albergando la misma cantidad de habitantes" (Cárdenas, 2015: 96). Solo el 15\% de los familias afectadas utilizaron el subsidio de construcción en sitio propio, a diferencia del subsidio de adquisición de vivienda, utilizado por el $43 \%$ de los afectados (Letelier y Boyco, 2011). En los barrios Chorrillos y Las Heras, localizados en el área centro-norte de Talca, con un total de 3.530 habitantes y en 411 viviendas, tres cuartas partes de las viviendas sufrieron daños severos y la mitad tuvieron que ser demolidas. Como consecuencia de ello, las familias más empobrecidas y en condición de arrendatarios, sin ahorros ni capacidad de endeudamiento, tuvieron que optar por los subsidios de adquisición de vivienda construida en áreas de densificación urbana. Esto implicó que los residentes fueran desplazados hacia nuevos barrios periféricos, pasando de las generalmente espaciosas viviendas antiguas del centro a departamentos que no superan los $47 \mathrm{~m}^{2}$. A este "desplazamiento subsidiario", alejado de las necesidades y requerimientos de las comunidades, se suma la proliferación de nuevos proyectos del tipo condominio cerrado para clases medias que se han localizado en el área central desde el 2010 a la fecha (Figura N4). Más de quince nuevos proyectos de vivienda en alta densidad para clases medias se han iniciado en los barrios céntricos más afectados por el terremoto, implicando una revalorización exponencial de los suelos. En comparación con los anteriores casos, sin una intervención de carácter social contundente por parte del Estado, la decisión racional de los agentes privados empuja a un aburguesamiento progresivo de un sector central que, a raíz del terremoto, ofrece oportunidades para la reconstrucción siguiendo un patrón acorde con los gustos actuales de la demanda solvente. 


\section{El rol estratégico de los desastres naturales en los procesos urbanos}

Los casos muestran la importancia determinante de los distintos eventos catastróficos para las estrategias de renovación urbana y, en general, para el cambio histórico de las áreas centrales de estas ciudades. De cara a la renovación urbana de los sectores centrales, el proceso destructivo ha definido invariablemente las características del espacio sobre las que ha operado la política pública.

Existen al menos tres aspectos, relacionados con el declive generalizado de las áreas centrales, que parecen resultar determinantes para las estrategias de renovación urbana en cuanto a eliminación de barreras para la entrada de futuras rondas de inversión de capital. En primer lugar, las pérdidas de población y el deterioro de las estructuras generan una alarma social que justifica la sobreinversión de las áreas centrales por parte del agente público (en relación a la inversión en otros lienzos de ciudad), eludiendo parcialmente la dificultad de un proceso de renovación organizado por múltiples propietarios privados, en áreas donde la propiedad tiende a estar muy atomizada. Estas inversiones públicas han resultado determinantes a la hora de generar un efecto contagio y se apoyan mutuamente con las inversiones privadas, dirigiendo la recapitalización y la revalorización de sectores estratégicos de la ciudad. En segundo lugar, la eliminación de estructuras edilicias previas elimina el obstáculo físico de un capital inmovilizado y sometido a una paulatina desvalorización. La edificación se convierte en mayor medida en una trampa para el capital invertido en entorno construido en función de las medidas regulatorias que intentan controlar el tipo de intervenciones permitidas. Esto se evidencia en el impedimento que suponían para la inversión de capital privado las normativas y la vigilancia proteccionista en Ciudad de México y en Sevilla, lo cual fue un objeto de conflicto entre distintos enfoques políticos en ambos casos.

La edificación patrimonial dificultaba la demolición e incrementaba hasta un grado altísimo los costes del reacondicionamiento. De cualquier forma, la proliferación de solares, edificios en situación de ruina susceptibles de ser derribados o instalaciones en situación de irregularidad dominial (Ciudad de México), como resultado (en parte) de los fenómenos catastróficos, genera invariablemente un campo para el rediseño urbanístico y la aparición de nuevas construcciones adaptadas a nuevos estándares urbanísticos y estéticos. Finalmente, el desplazamiento de residentes y el filtrado hacia abajo dan lugar a vecindarios débiles y envejecidos, fáciles de desplazar y con poca capacidad de resistirse a los cambios. No en vano, la presencia de clases populares en las áreas centrales se ha planteado por lo general como un obstáculo para su revitalización, se ha buscado su expulsión de forma activa y, cuando se han organizado, han planteado dificultades a las operaciones del capital inmobiliario privado. Los tres casos muestran un uso estratégico del espacio donde los fenómenos catastróficos son factores inesperados pero determinantes.

Estos fenómenos implican dentro de la lógica de circulación del capital en entorno construido, procesos de destrucción creativa, que eliminen espacios físicos y sociales preexistentes, permitiendo de esta manera su reconstrucción y recreación de acuerdo a nuevos estándares y necesidades. El desastre natural provoca la aceleración de la desvalorización de estos espacios, tanto subjetiva como objetiva, con una evidente pérdida de valores de uso que hace caer la renta capitalizada. La renta efectivamente capitalizada en el contexto previo a la intervención y a los procesos de revalorización se reduciría casi a 0 en muchos casos, entre edificios ruinosos, solares, edificios ocupados o habitados por inquilinos con rentas meramente simbólicas (rentas congeladas). A esto se suman los procesos de estigmatización que habrían contribuido a alejar a la demanda solvente de la zona. Esta situación puede favorecer en ocasiones los procesos de compra por parte de capitalistas frente a pequeños propietarios o residentes-propietarios. Ante la revalorización posterior de estos enclaves, iniciada a partir de la intervención pública y su contagio a los agentes privados, podríamos hablar de un rent gap que, como mínimo, permite notorias ganancias especulativas a aquellos agentes bien establecidos en el mercado.

No obstante, la respuesta del agente público muestra una notoria diversidad, en la geografía y en el tiempo, y no puede reducirse a una respuesta a los intereses de la circulación de capital. Más allá del interés de estos proce- 
sos para el capital inmobiliario y el urbanismo neoliberal, siguiendo los casos comentados, los acontecimientos catastróficos resultan ser un factor que también puede jugar un papel importante de cara a estrategias progresistas, orientadas a conseguir la permanencia de las clases populares en centro urbano y/o a la obtención de mejores condiciones de habitación. Los acontecimientos catastróficos han generado momentos políticos excepcionales que pueden servir para potenciar aquellos discursos, prácticas y espacios organizativos guiados por la solidaridad y la defensa de la población más vulnerable. Al menos en los casos de Ciudad de México y Talca, los terremotos han tenido como efecto positivo inesperado el fortalecimiento y la activación de las organizaciones vecinales, dando lugar a procesos de participación política con efectos notorios sobre el urbanismo local. En los casos de Ciudad de México y Sevilla, la reconstrucción posterremoto, ha implicado además las políticas de vivienda pública probablemente más ambiciosas de sus respectivas historias, determinantes para el desarrollo urbano posterior de ambas ciudades.

En términos generales, es factible la distinción entre un marco de intervención pública preneoliberal y otro neoliberal, un quiebre que se produce entre las décadas de los ochenta y noventa. Las intervenciones en Sevilla y Ciudad de México entre las décadas de los sesenta y ochenta muestran un urbanismo que implica procesos redistributivos relevantes a través de la provisión de vivienda para clases populares, con diferencias notables también entre sí respecto a la localización o la calidad del realojo. Asimismo, resulta determinante para las políticas de renovación urbana, las tendencias conservacionistas en materia de patrimonio histórico que, de manera temporal, se impusieron por encima de los intereses puramente pecuniarios. La intervención en el marco neoliberal por su lado implica un cambio notable respecto de las anteriores tendencias.

En este contexto resulta mucho más clara la funcionalidad del urbanismo de cara a facilitar estrategias de apropiación de rentas y de refuncionalización de enclaves estratégicos de cara al consumo. En la medida en que las operaciones de renovación más recientes siguen una racionalidad de mercado, la expulsión de los grupos de menores ingresos y la atracción de consumidores solventes resulta lógica, razón por la cual la gentrificación pasa a ser un proceso cada vez con mayor peso (Cuadro $\mathrm{N}^{\circ} 2$ ).

Cuadro $\mathrm{N}^{\circ} 2$

Acontecimiento catastrófico y políticas urbanísticas

\begin{tabular}{|c|c|c|c|}
\hline Elementos de análisis & Inundación Sevilla, 1961 & $\begin{array}{c}\text { Terremoto México, } \\
1985\end{array}$ & $\begin{array}{l}\text { Terremoto Talca, } \\
2010\end{array}$ \\
\hline $\begin{array}{l}\text { Efectos de la catástrofe } \\
\text { natural }\end{array}$ & $\begin{array}{l}125.000 \text { damnificados. } \\
4.127 \text { viviendas dañadas. } \\
29.386 \text { viviendas insa- } \\
\text { lubres }\end{array}$ & $\begin{array}{l}125.000 \text { damnifica- } \\
\text { dos. } \\
3.800 \text { viviendas da- } \\
\text { ñadas. }\end{array}$ & $\begin{array}{l}8.457 \text { damnificados. } \\
6.000 \text { viviendas da- } \\
\text { ñadas. } \\
1.700 \text { viviendas de- } \\
\text { molidas. }\end{array}$ \\
\hline Situación previa & \multicolumn{3}{|c|}{$\begin{array}{l}\text { Procesos de degradación y desinversión del entorno construido en las } \\
\text { áreas centrales, con carácter previo. } \\
\text { Pérdida de población durante la mayor parte del siglo XX y envejeci- } \\
\text { miento. } \\
\text { Éxodo de población de clase media-alta y ocupación de población me- } \\
\text { nores recursos en el centro. }\end{array}$} \\
\hline
\end{tabular}




\begin{tabular}{|c|c|c|c|}
\hline $\begin{array}{l}\text { Intervención en políti- } \\
\text { ca urbana en el marco } \\
\text { intervencionista, pre- } \\
\text { neoliberal }\end{array}$ & $\begin{array}{l}\text { Operaciones de renova- } \\
\text { ción urbana funcionalis- } \\
\text { ta: sustitución de pobla- } \\
\text { ción. } \\
\text { Reubicación de pobla- } \\
\text { ción popular del centro } \\
\text { urbano en viviendas so- } \\
\text { ciales periféricas. } \\
\text { Políticas conservacionis- } \\
\text { tas como obstáculo a la } \\
\text { renovación urbana pri- } \\
\text { vada }\end{array}$ & $\begin{array}{l}\text { Programas de Reno- } \\
\text { vación Habitacional } \\
\text { Popular: reubicación } \\
\text { de las clases popu- } \\
\text { lares dentro de las } \\
\text { áreas centrales. } \\
\text { Influencia del fuerte } \\
\text { movimiento vecinal. } \\
\text { Políticas conserva- } \\
\text { cionistas como obs- } \\
\text { táculo a la renova- } \\
\text { ción urbana privada. }\end{array}$ & \\
\hline $\begin{array}{l}\text { Intervención en políti- } \\
\text { ca urbana en el marco } \\
\text { neoliberal }\end{array}$ & $\begin{array}{l}\text { Intervención pública en } \\
\text { regeneración de espacios } \\
\text { públicos. } \\
\text { Proliferación de renova- } \\
\text { ción urbana por peque- } \\
\text { ños agentes privados. }\end{array}$ & $\begin{array}{l}\text { Refuncionalización } \\
\text { y rehabilitación de } \\
\text { espacios públicos. } \\
\text { Creación de ofer- } \\
\text { ta de vivienda para } \\
\text { clases medias. } \\
\text { Inversión público- } \\
\text { privada: Fundación } \\
\text { Centro Histórico } \\
\text { (Carlos Slim). }\end{array}$ & $\begin{array}{l}\text { Planeamiento estra- } \\
\text { tégico, no vinculan- } \\
\text { te. } \\
\text { Política de Recons- } \\
\text { trucción } 2010 \text {. Ac- } \\
\text { ceso a la vivienda } \\
\text { con endeudamiento. } \\
\text { Relocalización de } \\
\text { familias de estratos } \\
\text { populares en vivien- } \\
\text { das sociales perifé- } \\
\text { ricas. }\end{array}$ \\
\hline
\end{tabular}

Fuente: Elaboración propia.

\section{Conclusiones}

Desastres naturales, destrucción creativa y gentrificación parece ser una tríada presente en las ciudades -sean estas metrópolis o ciudades intermedias- que han tenido que reconstruir sus centros urbanos con posterioridad a una catástrofe natural. En ese sentido, ante las interrogantes planteadas en esta investigación, resulta veraz afirmar la existencia de una relación entre desastres naturales y gentrificación, al igual que entre renovación urbana y gentrificación. En los distintos casos, la existencia de regularidades puede adjudicarse al efecto de las lógicas propias de la producción de ciudad capitalista, que van más allá del acontecimiento puntual y de la particularidad de la urbe. Estas son las que identificamos con la idea de destrucción creativa, para referir la descapitalización y destrucción del espacio físico y social que queda obsoleto para los intereses del capital privado y su reinversión mediante procesos de renovación. La destrucción de las estruc- turas físicas y de los espacios sociales es un proceso lento, que sigue los ciclos de inversión y desinversión del capital, y que puede verse acelerado por la existencia de acontecimientos catastróficos.

El urbanismo, por su parte, parece ponerse, especialmente en las últimas décadas, al servicio de las lógicas propias del mercado. Así, los procesos de reconstrucción más reciente han priorizado las ganancias por encima de las necesidades del conjunto de los habitantes, con políticas públicas que -para el caso de Talca- han podido ser incluso los principales factores de expulsión para los damnificados hacia sectores periféricos. No obstante, estas generalizaciones no pueden abstraerse de contextos y agentes particulares. Si la idea de destrucción creativa planteada en relación al desarrollo urbano empezó por asociarse (no solo) a las típicas operaciones de renovación urbana funcionalista, la creciente vinculación de renovación urbana de áreas centrales y gentrificación 
es resultado de la aplicación de este tipo de políticas en un marco neoliberal. Esto ha quedado patente en los casos estudiados con mayor profundidad histórica, donde el mismo acontecimiento catastrófico ha servido en un contexto para una renovación urbana con una fuerte orientación social y redistributiva, y en otro contexto más reciente para una renovación liderada por los agentes privados y orientada por criterios de rentabilidad que parecen inevitablemente conducir a los enclaves centrales a su aburguesamiento.

Los procesos de reinversión en los tres casos tratados no pueden concebirse si no es como una estrategia consciente desarrollada en gran medida por el Estado, con la colaboración indispensable del capital privado. No responden a ningún tipo de resultado mecánico. Los desastres naturales se tienen en cuenta dentro de las estrategias de urbanización. Esta perspectiva es bastante clara en los agentes privados propietarios, con capacidad de especular con sus propiedades, así como de la administración pública a la hora de plantear la refuncionalización de determinados sectores estratégicos. Sin embargo, los casos tratados muestran cómo las organizaciones populares se convierten también en agentes que utilizan el terremoto y sus efectos estratégicamente, a la hora de reclamar vivienda y un lugar en la ciudad construida para la población de bajos ingresos. Los efectos de la influencia política de las organizaciones populares llegan hasta el día de hoy y dificultan procesos contemporáneos de aburguesamiento y desplazamiento. La cuestión de fondo aquí es de qué forma se plantea la reconstrucción necesaria frente a este tipo de acontecimientos puntuales pero con efectos duraderos y en beneficio de quién. De igual forma que los desastres naturales pueden liberar espacios centrales de habitantes indeseables para el capital, también pueden ser utilizados para mejorar las infraestructuras y corregir los problemas de infravivienda que habitualmente se han concentrado en estas áreas, mediante una intervención social y no de mercado.

Es, por lo tanto, sustancial obtener políticas integrales y planes que aminoren las vulnerabilidades que se generan especialmente en las primeras fases de un proceso de reconstrucción como es la recuperación y primera rehabilitación de los centros urbanos. En este sentido, los gobiernos encaran uno de los aspectos claves para entregar políticas urbanas y estratégicas adecuadas las cuales incluyan subsidios para ayudar a las personas que quedaron sin una vivienda, incentivos a inversores interesados en recobrar ciudades integrales y con diseño urbano, y oportunidades para incluir los activos de comunidades, resiliencia y sus identidades (Davoudi \& Porter 2012; PNUD 2010; Moser et al., 2011).

\section{Referencias bibliográficas}

AUTORIDAD DEL CHCM. Plan integral de manejo del Centro Histórico de 2011. Ciudad de México: Gobierno del DF, 2011.

BERMAN, M. Todo lo sólido se desvanece en el aire. La experiencia de la modernidad. Ciudad de México: Siglo XXI, 2011.

BRENNER, N. New States Spaces. Urban Governance and the Rescaling of Statehood. New York: Oxford University Press, 2004.

CASTILLO, M. Sevilla y el Tamarguillo: las medidas urbanísticas de urgencia cincuenta años después. Espacio y Tiempo. Revista de Ciencias Humanas, 2013, № 27, p. 51-74.

CÁRDENAS, A. Desplazamiento subsidiario del $27 f$ de 2010. Efectos socio-espaciales y normativos de la reconstrucción en Talca: el caso de los barrios Chorrillos y Las Heras. Santiago de Chile: Seminario de investigación, Facultad de Arquitectura y Urbanismo, Universidad de Chile, 2015.

CARDOSO, D. El distrito municipal I de Sevilla. Historia y Arte. Sevilla: Ayuntamiento de Sevilla, 1983.

CARRIÓN, F. Las nuevas tendencias de la urbanización en América Latina. Quito: FLACSO, 2012.

COLLER, X. Estudios de Caso. Cuadernos Metodológicos del CIS no 30. Madrid: CIS, 2005.

CONTRERAS, Y. La recuperación urbana y residencial del centro de Santiago: Nuevos habitantes, cambios socioespaciales significativos. EURE, 2011, Vol. 37, № 112, p. 89-113. 
DAVOUDI, S. \& PORTER, L. Applying the Resilience Perspective to Planning: Critical Thoughts from Theory and Practice. Planning Theory \& Practice, 2012, Vol. 13, N², p. 299-333.

DELGADILLO, V.; DÍAZ, I. y SALINAS, L. Perspectivas del estudio de la gentrificación en México y América Latina. Ciudad de México: Instituto de Geografía-UNAM, 2015.

DELGADILLO, V. Patrimonio histórico y tugurios. Las políticas habitacionales y de recuperación de los centros históricos de Buenos Aires, Ciudad de México y Quito. Ciudad de México: UACM, 2012.

DELGADILLO, V. Repoblamiento y recuperación del centro histórico de la ciudad de México, una acción pública híbrida, 2001 2006. Economía, Sociedad y Territorio, 2008, Vol. 28, Nº, p. 817-845.

DÍAZ, I. Segregación, intervención urbanística y cambio social en Sevilla. Sevilla: tesis doctoral, Facultad de Geografía e Historia, Universidad de Sevilla, 2011.

DÍAZ, I. Desplazamiento, acoso inmobiliario y espacio gentrificable en el caso de Sevilla. Encrucijadas. Revista Crítica de Ciencias sociales, 2012, № 2, p. 48-68

DÍAZ, I. El regreso a la ciudad consolidada. Ciudades. Análisis de coyuntura, teoría e historia urbana, 2014, No 103, p. 25-32.

DÍAZ, I. La mezcla improbable. Regreso a la ciudad y gentrificación en el Centro Histórico de Ciudad de México. Quid 16, 2015, Nº 5, p. 229-254.

DÍAZ DEL OLMO, F. y ALMOGUERRA, P. Sevilla, la ciudad y la riada del Tamarguillo (1961). Sevilla: Universidad de Sevilla, 2014.

DUCCI, M.E. El terremoto de México y las tareas de reconstrucción ¿Una lección para América Latina? EURE, 2014, No 38, p. 35-45.

DUHAU, E. La formación de una política social: el caso del Programa de Renovación Habitacional Popular en la ciudad de México. Estudios Demográficos y Urbanos, 1987, Vol. 1, No 4, p. 75-100.
FLÓREZ, A. Cuando el agua arrasó Sevilla. Abc de Sevilla, 2011. Disponible en Internet: http://sevilla.abc.es/20111125/sevilla/sevicuando-agua-arraso-sevilla-201111242226. html

GARCÍA JAÉN, P. Aplicaciones de la iniciativa comunitaria Urban. Boletín de la Asociación de Geógrafos Españoles, 1998, Vol. 12, $\mathrm{N}^{\circ} 26$, p. 191-206.

GDF, GOBIERNO DEL DISTRITO FEDERAL. Programa Delegacional de Desarrollo Urbano de Cuauhtémoc. Ciudad de México: Gobierno del DF, 2008.

GONZÁlEZ DORADO, A. Sevilla: centralidad regional y organización interna de su espacio. Madrid: Moneda y Crédito, 1975.

HACKWORD, J. \& SMITH, N. The Changing State of Gentrification. Tijdschrift voor Eonomische en Sociale Geoprafie, 2001, № 22, p. 464-477.

HARVEY, D. The Limits to Capital. London: Verso, 1982.

HARVEY, D. The Urbanization of Capital. Oxford: Basil Blackwell Ltd, 1985.

HARVEY, D. La condición de la postmodernidad. Buenos Aires: Amorrortu, 1990.

HARVEY, D. Espacios de esperanza. Madrid: Akal, 2003.

HARVEY, D. Paris, Capital de la Modernidad. Madrid: Akal, 2008.

HIERNAUX-NICOLÁS, D. Los frutos amargos de la globalización: expansión y reestructuración metropolitana de la ciudad de México. EURE, 1999, Vol. 25, № 76, p. 57-78.

INZULZA-CONTARDO, J. 'Latino-Gentrificación'? Focusing on Physical and Socioeconomic Patterns of Change in Latin American Inner Cities. Urban Studies, 2012, Vol. 49, N ${ }^{\circ}$ 10, p. 2085-2017.

INZULZA-CONTARDO, J. La recuperación del diseño cívico como reconstrucción de lo local en la ciudad intermedia: el caso de Talca, Chile. Revista AUS, 2014, № 16, p. 4-8. 
IRACHETA, A. Una visión de la planeación mexicana. En: GONZÁLEZ LÓPEZ, S. (coordinador). Desarrollo regional y urbano en México a finales del siglo XX (Tomo II). Análisis y planeación del desarrollo urbano y regional. Ciudad de México: UNAM, 1998, p. 23-49.

JANOSCHKA, M.; SEQUERA, J. \& SALINAS, L. Gentrification in Spain and Latin America - a Critical Dialogue. International Journal of Urban and Regional Research, 2013, Vol. 28, N4, p. 1234-1265.

LETELIER, F. y BOYCO, P. Talca a tres años del terremoto: aprendizajes colectivos para la acción en la ciudad. Temas Sociales, 2013, $\mathrm{N}^{\circ}$ 70. Disponible en Internete: http://www. sitiosur.cl.

LETELIER, F. y BOYCO, P. Talca posterremoto: una ciudad en disputa. Modelo de reconstrucción, mercado inmobiliario y ciudadanía. Santiago de Chile: Ediciones SUR, 2011.

LÓPEZ-MORALES, E. Urbanismo pro empresarial y destrucción creativa: Un estudio de caso de la estrategia de renovación urbana en el pericentro de Santiago de Chile, 19902005. Ciudad de México: Infonavit-Redalyc, 2012.

LOZANOVKSA, M. Kenzo Tange's Forgotten Master Plan for the Reconstruction of Skopje, Fabrications. The Journal of the Society of Architectural Historians, Australia and New Zealand, 2012, Vol. 22, №2, p. 140-163.

MARCUS, J.; AQUINO, M.; BENÍTEZ, J.; FELICE, M. y MÁRQUEZ, A. Procesos de vaciamiento y destrucción creativa en un barrio de la Ciudad de Buenos Aires. El caso de los exterrenos ferroviarios y los predios adyacentes. Area, 2014, № 20, 75-85.

MARÍN DE TERÁN, L. Sevilla, centro urbano y barriadas. Sevilla: Ayuntamiento de Sevilla, 1980.

MINISTERIO DE VIVIENDA Y URBANISMO (MINVU). Avance en la entrega de soluciones habitacionales. Programa de Re- construcción en Vivienda. Santiago de Chile: MINVU, Informe Marzo, 2013.

MOSER, C.; SOU, G. \& STEIN, A. Climate change and assets. In: Briefing Paper 2. Manchester: Global Urban Research Centre, University of Manchester, 2011.

PROGRAMA DE LAS NACIONES UNIDAS PARA EL DESARROLLO (PNUD). Gestión de Riesgo Urbano, Buró de Prevención de Crisis y Recuperación. 2010. Disponible en Internet: http://www.undp.org.

PROGRAMA DE LAS NACIONES UNIDAS PARA EL DESARROLLO (PNUD). Un informe mundial. La reducción de riesgos de desastres. Un desafío para el Desarrollo. Buffalo Grove: Dirección de Prevención de Crisis y de Recuperación \& John S. Swift Co., 2004.

PROGRAMA DE DESARROLLO INTEGRAL-CORREDOR URBANO CENTRO HISTÓRICO DE LA CIUDAD DE MÉXICO (PDICHCM). Programa para el desarrollo integral del CHCM. Ciudad de México: Fideicomiso CHCM, 2000.

RASSE, A. y LETELIER, F. El proceso de reconstrucción de viviendas en el centro de Talca: fotografía a dos años de la catástrofe. Revista INVI, 2013, Vol. 28, Nº77, p. 139-164.

RUIZ, J.L. Triana, historia urbana y personalidad geográfica. Sevilla: Ayuntamiento de Sevilla, 2005.

ROJAS, E. Volver al Centro. La Recuperación de las Urbanas Centrales. Washington, D.C.: Banco Interamericano de Desarrollo, 2004.

SMITH, N. The New Urban Frontier: Gentrification and the Revanchist City. London \& New York: Routledge, 1996.

SCHUMPETER, J.A. Capitalismo, socialismo y democracia. Barcelona: Orbis, 1988.

VALENZUELA, A. Dispositivos de la globalización: la construcción de grandes proyectos urbanos en Ciudad de México. EURE, 2013, Vol. 39, No 116, p. 101-118. 